\title{
FBP1 modulates cell metabolism of breast cancer cells by inhibiting the expression of HIF-1a
}

\author{
L. SHI ${ }^{1}$, C. $\mathrm{HE}^{1}$, Z. $\mathrm{LI}^{2}$, Z. WANG ${ }^{2, *}$, Q. ZHANG ${ }^{3, *}$ \\ ${ }^{1}$ Department of Radiation Oncology, The Fourth Hospital, Harbin Medical University, 37 Yiyuan Street, Harbin 150001, China; ${ }^{2}$ Department of \\ Ultrasound, The Second Affiliated Hospital of Harbin Medical University, 246 Xuefu Road, Harbin 150001, China; ${ }^{3}$ Department of Oncology, \\ The Third Hospital, Harbin Medical University, 150 Haping Road, Harbin 150080, China
}

*Correspondence: welcomezhen126@126.com,qingyuanzhang23@hotmail.com

Received September 23, 2016 / Accepted January 17, 2017

\begin{abstract}
This study aimed to investigate the function of fructose-1, 6-bisphosphatase 1 (FBP1) in regulating cell growth and metabolism through hypoxia-inducible factor $1 \alpha$ (HIF-1a)-dependent hypoxic response in breast cancer cells. Two human breast carcinoma cell lines, including luminal-like cell line MCF-7 and basal-like cell line MDA-MB-468, were cultured under hypoxia condition, then the expressions of FBP1 and HIF-1 $\alpha$ were detected by western blotting. In addition, upregulated FPB1 in MDA-MB-468 cells were induced by lentivirus. Next, cell growth, migration and glucose metabolism were evaluated by MTT assay, Transwell and commercial kits, as well as the expressions of HIF-1a target genes, including pyruvate dehydrogenase kinase 1 (PDK1), lactate dehydrogenase A (LDHA), glucose transporter 1 (GLUT1) and vascular endothelial growth factor (VEGF) were detected by RT-qPCR. Furthermore, chromatin immunoprecipitation was used to estimate whether the hypoxia response elements (HREs) of PDK1, LDHA, GLUT1 and VEGF promoters were incorporated with FBP1. FBP1 was downregulated in MDA-MB-468 cells compared with MCF-7 cells. Overexpression of FBP1 in MDA-MB-468 cells reduced cell growth $(p<0.05)$ and migration $(p<0.05)$ as well as glycose consumption $(p<0.05)$ and lactate production $(p<0.05)$. In addition, overexpressed FBP1 inhibited HIF-1 $\alpha$ protein expression and the mRNA levels of PDK1, LDHA, GLUT1 and VEGF $(p<0.05)$ under hypoxia condition. Also, FBP1 was revealed to have a concrete connection with PDK1. This study reveal that overexpressed FBP1 may repress tumor growth, migration and glycolysis via targeting HIF-1 $\alpha$ in BLBC.
\end{abstract}

Key words: basal-like breast carcinoma, hypoxia-inducible factor-1 $\alpha$, fructose-1, 6-bisphosphatase 1, glucose metabolism

Breast cancer is commonly diagnosed malignant disease in women and only second to lung cancer for cancer-related mortality worldwide $[1,2]$. A molecular taxonomy with DNA microarray has divided tumors into 5 types: luminal type $A$ and $B$, human epidermal growth factor receptor 2/neu type, normal breast-like, and basal-like breast cancer (BLBC) $[3,4]$. Lundgren et al., have demonstrated that the hypoxic regions are observed in about $25 \%-40 \%$ BLBC [5]. It is well-known that low oxygen of primary tumors is related to the elevated risks of metastasis and mortality in cancer patients, including breast cancer $[6,7]$. Thus, more efforts are still necessary to investigate the mechanisms of hypoxia and search for effective treatment methods in breast cancer.

Hypoxia inducible factors (HIFs) are considered as important molecules responding to hypoxia [8], and play a vital role in maintaining oxygen homeostasis in cancer cells [9].
HIF-1a, a dominant subunit of HIF-1, has been proved to mediate $\mathrm{O}_{2}$-dependent transcriptional responses [10]. When oxygen concentrations is below $6 \%$, HIF- $1 \alpha$ subunits bind to HIF-1 $\beta$ subunits [11], which can regulate the expressions of its downstream genes through binding with hypoxia responsive elements (HREs) of target genes promoter, thereby involving in cellular metabolism, tumor survival and metastasis $[12,13]$. It has been reported that patients with BLBC show increased expressions of HIF-1 $\alpha$ and its target genes, and have more necrosis and aggressive behavior than luminallike tumors [14-16]. Previous study has shown that cancer malignancy is associated with a shift of cellular metabolism from mitochondrial respiration to aerobic glycolysis in the presence of abundant oxygen [17]. HIF-1a has proved to be a key regulator of the glycolysis process and can contribute to gluconeogenesis [18]. Fructose-1, 6-bisphosphatase 1 
(FBP1) is a key regulatory enzyme during the process of gluconeogenesis $[19,20]$. It has been reported that deletion of FBP1 expression is found in liver, gastric and colon cancers, which can accelerate glucose uptake and glycolysis $[21,22]$. Compelling evidence indicates that increased FBP1 levels predicts a better outcome in various neoplastic disease, including kidney carcinoma [23], stomach carcinoma [22], lung carcinoma [24], suggesting that FBP1 plays a vital role in dominating glucose metabolism in cancers. Li et al. [23] have revealed that FBP1 suppresses renal cancer cell proliferation and glycolysis by restraining nuclear HIF function. However, few studies have investigated the interaction of HIF- $1 \alpha$ and FBP1 and the role of FBP1 in BLBC.

In the present study, two human breast carcinoma cell lines, including luminal-like cell line MCF-7 and basal-like cell line MDA-MB-468, were cultured under hypoxia condition. We investigated the effects of up-regulated FPB1 on cell growth, migration and glucose metabolism, as well as the expressions of HIF- $1 \alpha$ and its target genes, including pyruvate dehydrogenase kinase 1 (PDK1), lactate dehydrogenase A (LDHA), glucose transporter 1 (GLUT1) and vascular endothelial growth factor (VEGF), aiming to identify whether anticancer property of FBP1 was associated with down-regulated HIF-1 $\alpha$ in human breast cancer cells.

\section{Materials and methods}

Cell culture. MCF-7 cells and MDA-MB-468 cells were purchased from the Cell Bank of Chinese Academy of Sciences (CAS, Shanghai, China). The MDA-MB cells and the MCF-7 cells were maintained in L-15 medium (GIBCO, Grand Island, NY, USA) and DMEM medium (GIBCO), respectively, containing $10 \%$ heat-inactivated fetal bovine serum (GIBCO), $100 \mathrm{U} / \mathrm{mL}$ penicillin and $100 \mu \mathrm{g} / \mathrm{mL}$ streptomycin (Beyotime Institute of Biotechnology, Nanjing, China). All cells were cultured at $37^{\circ} \mathrm{C}$ in a humidified atmosphere containing $5 \% \mathrm{CO}_{2}$.

Construction, packaging and infection of lentivirus vector. Human FBP1 gene was synthesized by Western Biotech Co., Ltd. (Shanghai, China) and two restriction sites, NotI and NsiI were added at opposite ends of the gene. Then the FBP1 gene was cloned into pGLV5-green fluorescent protein (GFP) lentiviral vector. Double enzyme digestion (NotI and $\mathrm{NsiI}$ ) and sequence analysis were used to confirm the positive recombinant clones of LV5-FBP1. The successfully constructed LV5-FBP1 or LV5-GFP empty vector were co-transfected with packaging plasmid (mix) into 293T cell using Lipofectamine 2000 (Invitrogen, Carlsbad, CA, USA). Packaging of lentivirus and measurement of virus titer were performed following the previous study [25]. The titer of the lentivirus LV5-FBP1 and LV5-GFP was $7 \times 10^{8} \mathrm{TU} / \mathrm{ml}$ and $5 \times 10^{8} \mathrm{TU} / \mathrm{ml}$, respectively. The lentivirus were stored at $-80{ }^{\circ} \mathrm{C}$ for the following experiments. MDA-MB-468 cells were infected with recombinant lentivirus LV5-FBP1 or control lentivirus LV5-GFP, with a multiplicity of infection (MOI) of 100 and $8 \mu \mathrm{g} / \mathrm{ml}$ polybrene (Sigma, St. Louis, MO, USA). MDA-MB-468 cells without infection were served as blank group. After transfection for $72 \mathrm{~h}$, cells were collected for subsequent analysis.

Cell grouping. MCF7 cells, MDA-MB-468 cells, MDAMB-468 cells with LV5-FBP1 (FBP1 transfection) and MDA-MB-468 cells with LV5-GFP (control lentivirus) were cultured under normoxia and hypoxia conditions, respectively. Hypoxia was induced by a stepwise oxygen-deprivation in a hypoxia chamber. The cells were kept for $24 \mathrm{~h}$ at $21 \% \mathrm{O}_{2}$ and for one day at $0.5 \% \mathrm{O}_{2}$ with constant $5 \% \mathrm{CO}_{2}$ and the remainder being $\mathrm{N}_{2}$.

Western blotting. Cells were collected, then nuclear protein and cytosolic protein were extracted using Nuclear/Cytosolic Fractionation Kit (Biovision, Palo Alto, CA, USA). Proteins were separated using SDS-PAGE, transferred onto PVDF membranes (Millipore, Milford, MA, USA), and then blocked in $5 \%$ nonfat milk. Next, the membranes were immunoblotted with mouse anti-human glyceraldehyde-phosphate dehydrogenase (GAPDH) monoclonal antibody, rabbit anti-human FBP1 and HIF-1a polyclonal antibodies (1:500, Abcam, Cambridge, MA, USA) overnight at $4^{\circ} \mathrm{C}$, and then incubated with corresponding second antibody (GenScript, Piscataway, NJ, USA) for $1 \mathrm{~h}$ at room temperature. Finally, stained bands were detected by enhanced chemiluminescence (Thermo, San Jose, CA, USA).

Metabolic assays. Glucose uptake and lactate production were measured by commercial kits (Nanjing Jiancheng Bioengineering Institute, Jiangsu, China) following the standard protocol. The glucose and lactate concentrations were measured according to the OD values at $505 \mathrm{~nm}$ and $530 \mathrm{~nm}$, respectively, using a microplate reader (Molecular Devices, USA).

MTT assay. The $1 \times 10^{5}$ cells were seeded into each well of a 96-well plate. The second day, the MDA-MB-468 cells were infected with lentivirus LV5-FBP1 or LV5-GFP, respectively, and then the cells were incubated for $48 \mathrm{~h}$ under normoxia or hypoxia conditions. MTT (10 $\mu \mathrm{l}, 5 \mathrm{mg} / \mathrm{mL}$ ) (Sigma) was added into each well at the same time every day and then the cells were incubated for 4 hours. Dimethyl sulfoxide (DMSO, $100 \mu \mathrm{l}$, Amresco, Solon, OH, USA) was later added into each well to solubilize the formazan crystals. MDA-MB-468 cells without lentivirus was served as control group. The absorbances were read at $490 \mathrm{~nm}$ using a microplate reader.

Migration assays. Migration of cells was detected using Transwell system with $8-\mu \mathrm{m}$ pores of inserts (Corning Costar, Lowell, MA, USA). The cells were plated onto control or Matrigel-coated membrane inserts. After treatment for $24 \mathrm{~h}$, cells were detached using cotton-tipped swabs. The migrated cells were fixed in methanol, and then $0.5 \%$ crystal violet was used to stain cells. Lastly, cell were counted under the microscope.

Real-time quantitative polymerase chain reaction (RTqPCR). The cells were collected and total RNA was isolated using Trizol reagent (Invitrogen, Carlsbad, CA, USA). Primers for PDK1, LDHA, GLUT-1, VEGF, and $\beta$-actin are shown in Table 1. PCR amplification was carried out on a SmartCy- 
cler (Western Biotechnology) using a SYBR Green reverse transcription-polymerase chain reaction kit (Western Biotechnology). Data were normalized with $\beta$-actin gene. Relative quantification and calculations were done with the comparative threshold $(C \mathrm{t})$ cycle method $\left(2^{-\Delta \Delta} \mathrm{Ct}\right)$.

Chromatin immunoprecipitation (ChIP) assay. ChIP assays were carried out using QuikChIP kit (Imgenex, San Diego, CA, USA). Briefly, protein-chromatin cross-linking of cells was induced using $1 \%$ formaldehyde for $10 \mathrm{~min}$ at $37^{\circ} \mathrm{C}$ and quenched by glycine. Then cells were lysed in lysis buffer and chromatin DNA from cell lysates were sonicated into fragments. Next, chromatin DNA fragments were subjected to immunoprecipitation with FBP1 antibody. After reverse cross-linking, DNA fragments were purified and then detected by RT-qPCR.

Statistical analysis. Statistical analysis software (SPSS 12.0, SPSS Inc., Chicago, IL, USA) was used in this study. Data were expressed as mean $\pm \mathrm{SD}$. The student's $t$-test was used to analyze the data. A value of $p<0.05$ was considered highly significant.

\section{Results}

Effect of FBP1 on HIF-1 $\alpha$ expression in MCF-7 and MDA-MB-468 cells under normoxia and hypoxia conditions. First, we detected the expression of FBP1 in MCF-7 and MDA-MB-468 cells, respectively, under normoxia (21\%) and hypoxia $(0.5 \%)$ conditions. Western blotting results showed that FBP1 protein levels between normoxia (21\%) and hypoxia $(0.5 \%)$ conditions were similar in cell nucleus and cytoplasm of MDA-MB-468 cells lines, respectively, and a similar trend was observed in MCF-7 cells (Figure 1A). In addition, compared with MDA-MB-468 cells, MCF-7 cells showed the increased basal level of FBP1 expression, and FBP1 expression in cytoplasm was higher than that in cell nucleus in both MDA-MB-468 and MCF-7 cells (Figure 1A). Thus, MDA-MB-468 cells were selected to be transfected with LV5FBP1 in the following experiments. The results revealed that both cell lines showed certain degree of induction of HIF-1a

Table 1. Primer sequence of PDK1, LDHA, GLUT-1, VEGF, and $\beta$-actin

\begin{tabular}{|c|c|c|}
\hline Gene & Primer sequence & $\begin{array}{l}\text { Product } \\
\text { size (bp) }\end{array}$ \\
\hline PDK1 sense & 5'-GACTGTGAAGATGAGTGACCGAG-3، & 146 \\
\hline PDK1 antisense & 5'-TGGGCAATCCATAACCAAAAC-3‘ & \\
\hline LDHA sense & 5'AAAACCGTGTTATTGGAAGCG-3‘ & 150 \\
\hline LDHA antisense & 5-TCATTCCACTCCATACAGGCAC-3‘ & \\
\hline GLUT-1 sense & 5'-GCTCATCAACCGCAACGAG-3‘ & 131 \\
\hline GLUT-1 antisense & $5^{\circ}$-TGACCTTCTTCTCCCGCATC- $3^{c}$ & \\
\hline VEGF sense & 5-AATCGAGACCCTGGTGGACA-3 & 143 \\
\hline VEGF antisense & 5-TGTTGGACTCCTCAGTGGGC-3‘ & \\
\hline$\beta$-actin sense & 5'TGACGTGGACATCCGCAAAG-3‘ & 205 \\
\hline$\beta$-actin antisense & 5'CTGGAAGGTGGACAGCGAGG-3‘ & \\
\hline
\end{tabular}
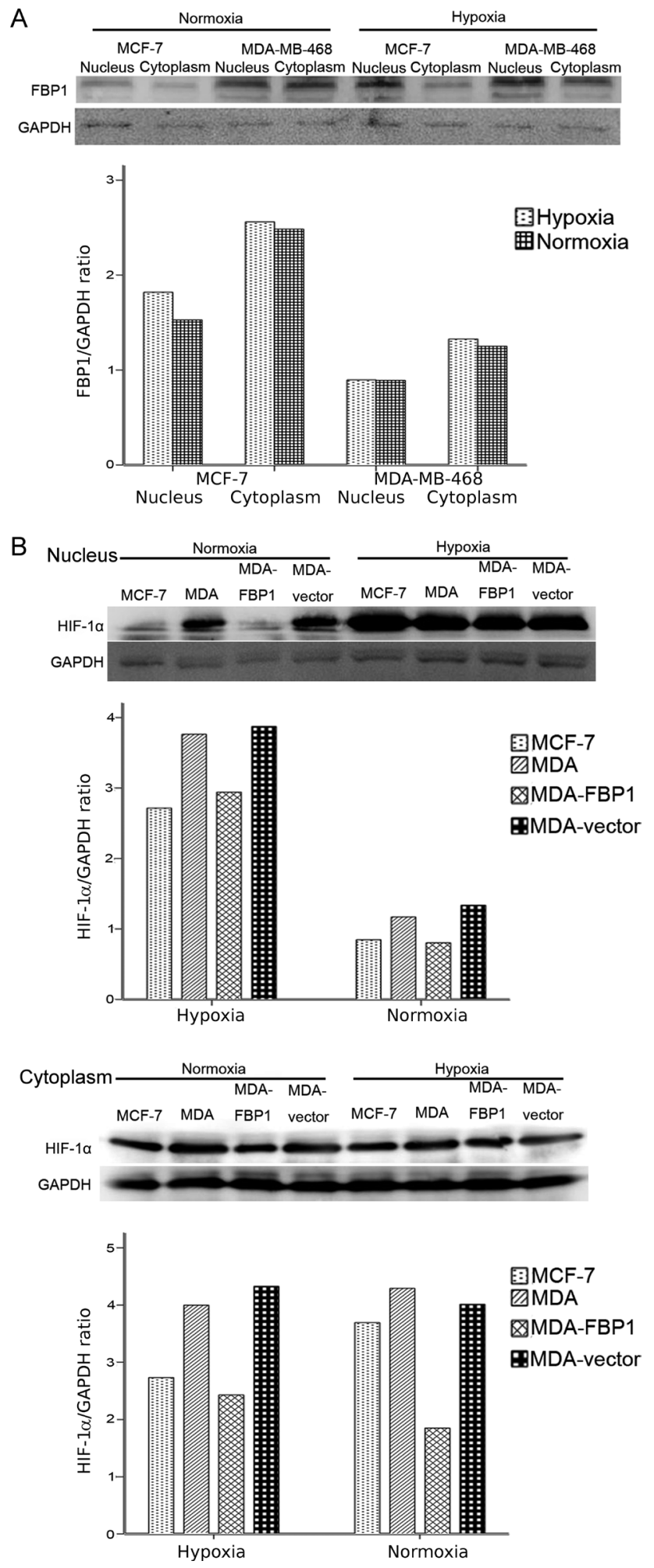

Figure 1. The protein expressions of FBP1 and HIF $1 \alpha$ in MCF-7 and MDAMB-468 cell lines. A, western blotting of FBP1 expression under normoxia and hypoxia conditions in breast cancer cell nucleus and cytoplasm. B, western blotting of HIF-1 1 expression under normoxia and hypoxia conditions in breast cancer cell nucleus and cytoplasm.

FBP1, fructose-1, 6-bisphosphatase 1; HIF-1 1 , hypoxia-inducible factor $1 \alpha$ 

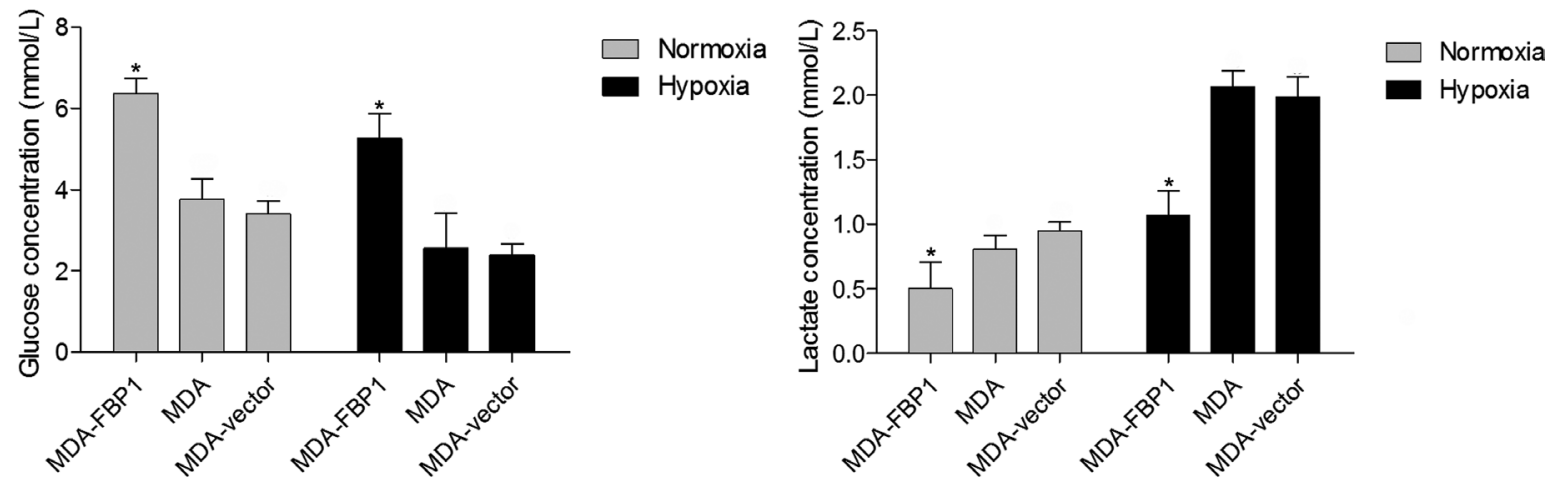

Figure 2. Glucose uptake and lactate production in MDA-MB-468 cells alone, MDA-MB-468 cells with LV5-GFP, and MDA-MB-468 cells with FBP1 transfection under normoxia and hypoxia conditions.

${ }^{*} \boldsymbol{P}<0.05$ versus MDA and MDA-vector

under hypoxia condition compared with normoxia condition in cell nucleus but not in cytoplasm (Figure 1B). In nucleus, MCF-7 cells showed the reduced HIF-1a expression under hypoxia condition and increased HIF-1 1 expression under normoxia condition compared with MDA-MB-468 cells, indicating MCF-7 showed an increased ability to respond to hypoxia (Figure 1B). Moreover, MDA-MB-468 cells with FBP1 transfection showed lower HIF-1a protein level than MDAMB-468 cells alone and MDA-MB-468 cells with LV5-GFP under normoxia condition (Figure 1B), which suggested the opposite expressions of FBP1 and HIF-1 $1 \alpha$ in human breast cancer cell lines.

Effect of up-regulated FBP1 on glucose uptake and lactate production in MDA-MB-468 cells under normoxia and hypoxia conditions. Metabolic assays found that glucose uptake was lower, while lactate production was higher in MDA-MB-468 cells under hypoxia condition than those under normoxia condition (Fig. 2). In addition, compared with MDA-MB-468 cells alone and MDA-MB-468 cells with LV5-GFP, MDA-MB-468 cells with FBP1 transfection showed significantly increased glucose uptake and decreased lactate production under either normoxia or hypoxia condition (all $p<0.05$, Figure 2).

Effect of up-regulated FBP1 on cell growth and migration in MDA-MB-468 cells under normoxia and hypoxia conditions. MTT assay showed that cell viability was higher in MDA-MB-468 cells under hypoxia condition than those under normoxia condition (Fig. 3A). Also, cell viability was reduced in MDA-MB-468 cells with FBP1 transfection compared with MDA-MB-468 cells with LV5-GFP (Fig. 3A) at 12, $24,48,72$ and $96 \mathrm{~h}$, and cell viability was increased in a timedependent manner. In addition, MDA-MB-468 cells with FBP1 transfection showed reduced cell migration compared with MDA-MB-468 cells alone and MDA-MB-468 cells with LV5-GFP both under normoxia and hypoxia conditions (all $p<0.01$, Figure 3B). Meanwhile, cells under hypoxia condition had increased cell migration compared with normoxia condition $(p<0.01$, Figure 3B).
Effect of up-regulated FBP1 on HIF-1a-target genes levels in MDA-MB-468 cells under hypoxia condition. To further investigate the relationship of FBP1 and HIF-1 $\alpha$ in human breast cancer cell lines, we detected the mRNA levels of HIF-1 $a$-target genes, including PDK1, LDHA, GLUT1 and VEGF. RT-qPCR results showed that the mRNA levels of PDK1, LDHA, GLUT1 and VEGF were significantly lower in MDA-MB-468 cells with FBP1 transfection than those in MDA-MB-468 cells alone and MDA-MB-468 cells with LV5-GFP under hypoxia conditions (all $p<0.05$, Figure 4A). Furthermore, ChIP assays revealed that FBP1 was enriched at the HRE of PDK1 promoter, but not the HREs of LDHA, GLUT1 and VEGF promoters (Figure 4B), indicating the concrete connection of FBP1 and PDK1.

\section{Discussion}

Hypoxic conditions are frequently present in breast carcinoma and are associated with poor prognosis [26]. The present study showed that overexpressed FBP1 significantly increased glucose uptake and decreased lactate production, as well as inhibited cell growth and migration under either normoxia or hypoxia condition. Furthermore, we found that overexpressed FBP1 inhibited HIF-1 1 p protein expression and the mRNA levels of PDK1, LDHA, GLUT1 and VEGF under hypoxia condition. Also, FBP1 was revealed to have a concrete connection with PDK1.

Although central to the hypoxic condition was the transcription factor HIF, HIF- $1 \alpha$ stabilization was imperative for the activation of HIF in solid tumors $[27,28]$. The nuclear expression of HIF- $\alpha$ had been proved to be associated with poor prognosis in many cancers [29]. Consistently, our study found that both MCF-7 and MDA-MB-468 cells showed the induction of HIF-1a under hypoxia condition compared in cell nucleus but not cytoplasm. In addition, this study found the opposite expressions of FBP1 and HIF-1a in human breast cancer cell lines, which was consistent with the previous study [23]. It had been reported that HIF-1a 
A
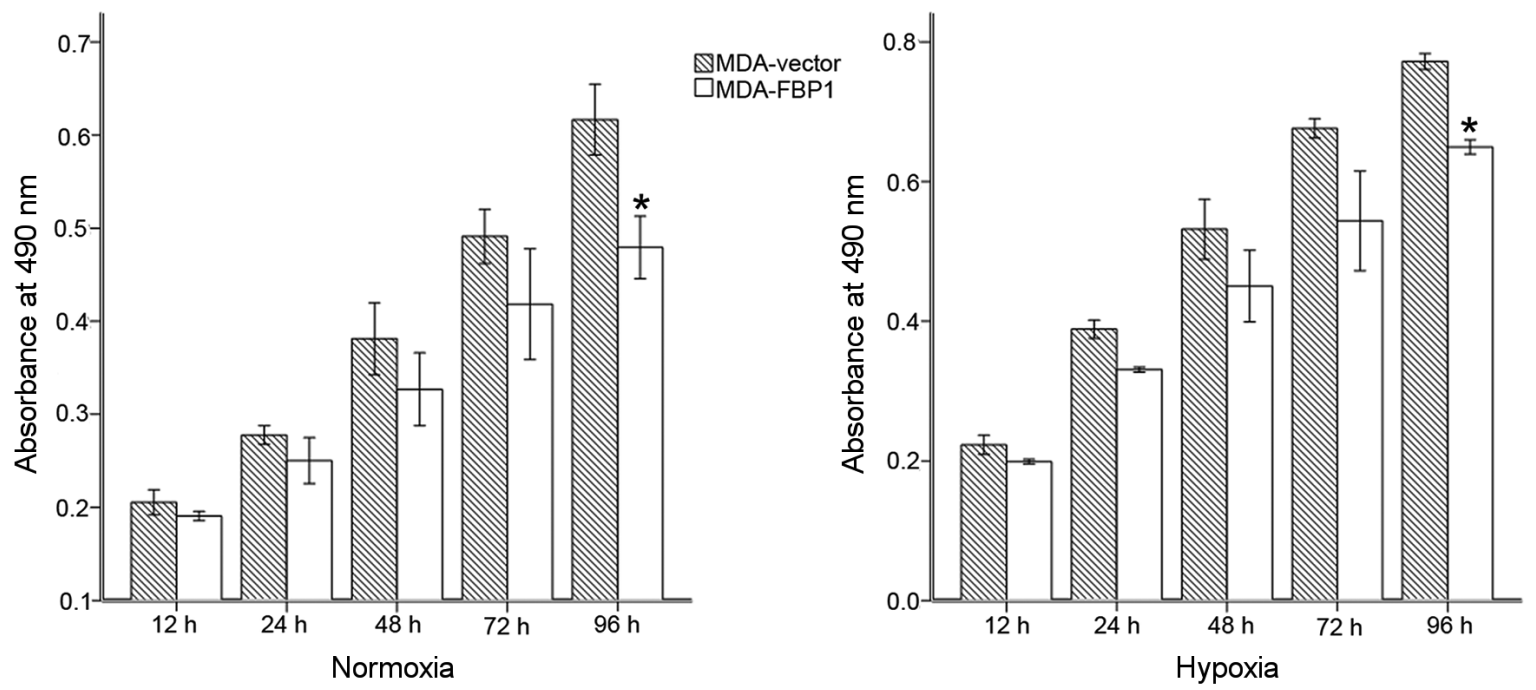

B
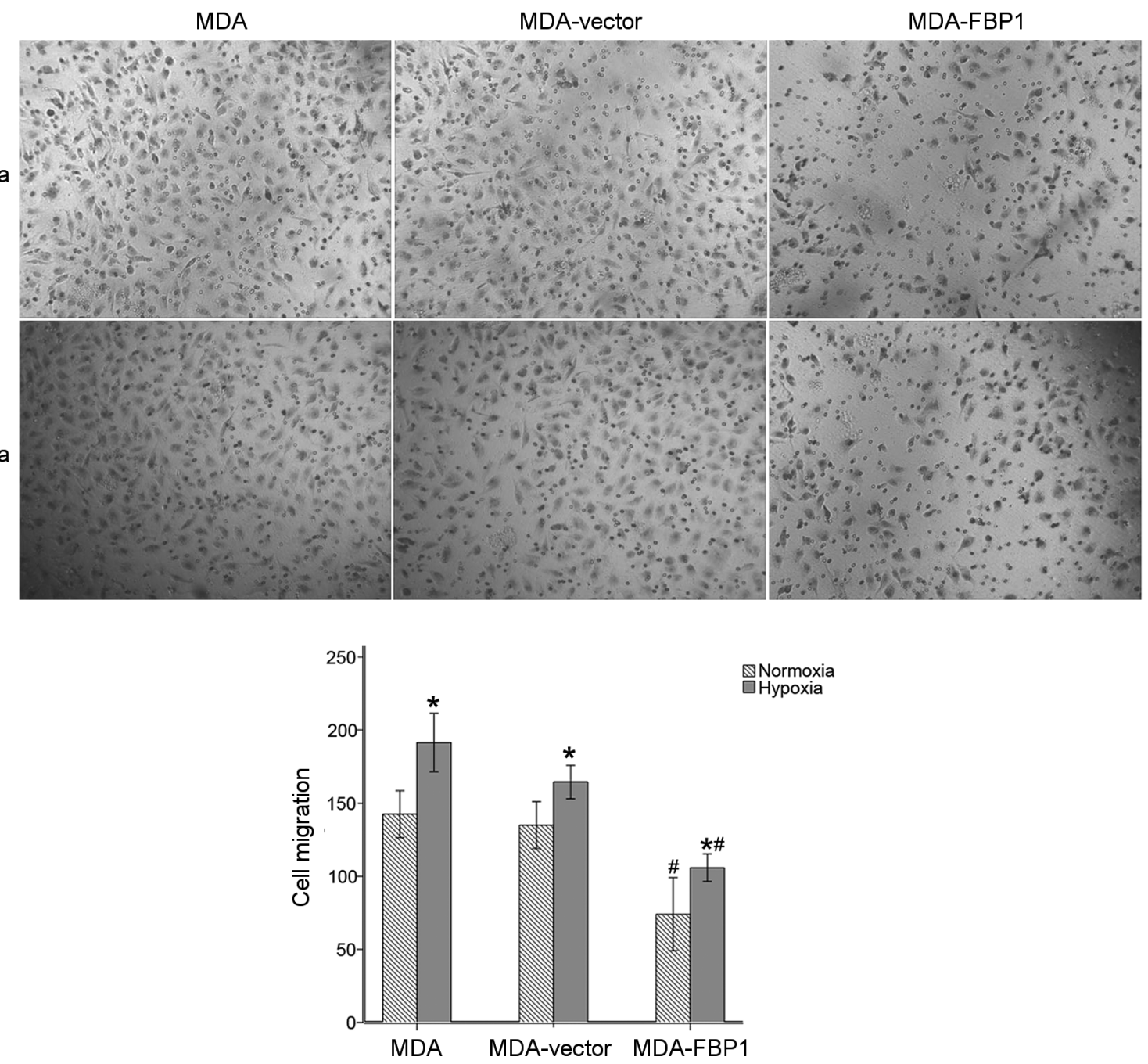

Figure 3. Overexpressed FBP1 reduced cell growth and migration under normoxia and hypoxia conditions. A, MTT assay showed the cell growth at 12, 24, 48, 72 and $96 \mathrm{~h}$ in MDA-MB-468 cells alone, MDA-MB-468 cells with LV5-GFP, and MDA-MB-468 cells with FBP1 transfection. B, Transwell assay showed the cell migration in MDA-MB-468 cells alone, MDA-MB-468 cells with LV5-GFP, and MDA-MB-468 cells with FBP1 transfection (magnification 100x). $A,{ }^{\star} P<0.05$ versus MDA-vector; $B,{ }^{*} P<0.05$ versus normoxia, ${ }^{\sharp} P<0.05$ versus MDA and MDA-vector. 
A

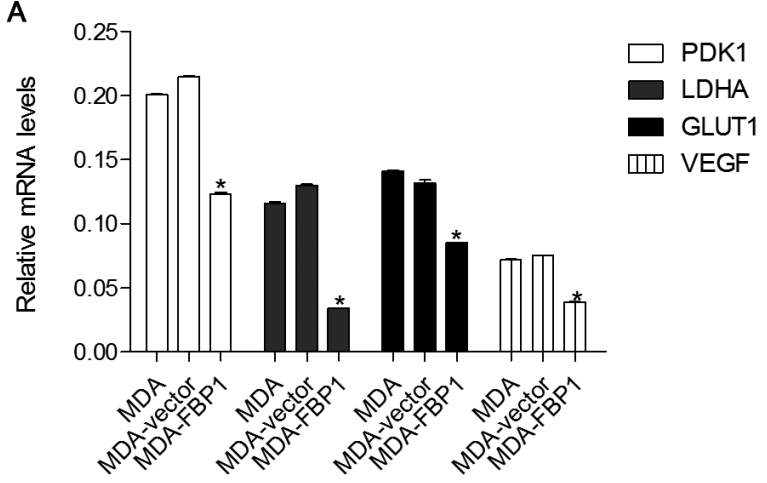

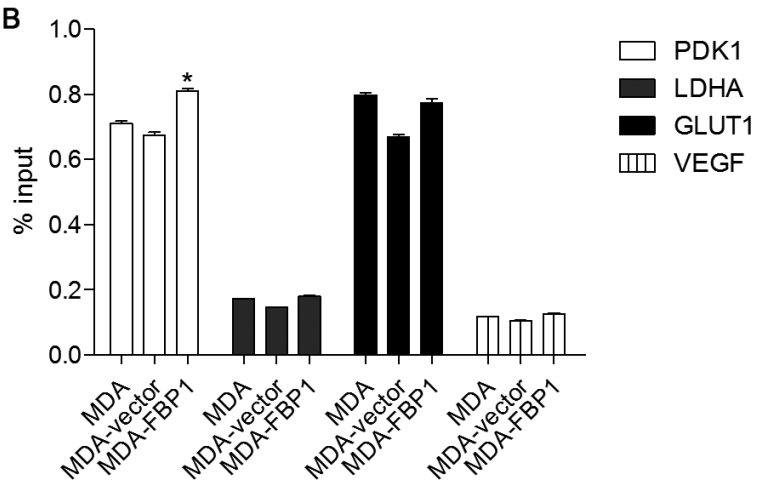

Figure 4. Overexpressed FBP1 reduced the mRNA levels of PDK1, LDHA, GLUT1 and VEGF under hypoxia condition. A, RT-qPCR showed the mRNA levels of PDK1, LDHA, GLUT1 and VEGF in MDA-MB-468 cells alone, MDA-MB-468 cells with LV5-GFP, and MDA-MB-468 cells with FBP1 transfection under hypoxia condition. B, chromatin immunoprecipitation revealed the connection of the hypoxia response elements (HREs) of PDK1, LDHA, GLUT1 and VEGF promoters with FBP1.

${ }^{\star} P<0.05$ versus MDA and MDA-vector

was overexpressed in common human cancers [27] and the inhibition of HIF-1a might be an anti-cancer methods by regulating cell growth, invasion and migration $[30,3]$. This study also found that overexpressed FBP1 inhibited cell growth and migration. In addition, we found that overexpressed FBP1 increased glucose uptake and decreased lactate production. Tumor glucose metabolism had been reported to be directly regulated by the related enzymes and transporters, which was also related to the suppression of HIF-1a [32]. Notably, HIF-1 inhibition could result in increased glucose uptake and decreased lactate production in vitro [33]. All these results indicated that overexpressed FBP1 might have an anti-cancer effect in breast cancer, which might be associated with HIF-1a.

To further investigate the mechanism of anti-cancer property of FBP1 and the relationship of FBP1 and HIF$1 \alpha$, we detected the expressions of HIF-1a target genes. The results showed that overexpressed FBP1 inhibited the mRNA levels of PDK1, LDHA, GLUT1 and VEGF under hypoxia condition. Similar to FBP1, PDK1, LDHA and GLUT1, regulated by HIF-1 $\alpha$, were key proteins related to cellular glucose metabolism. The activation of PDK and LDHA both could contribute to the conversion of glucose to lactate $[34,35]$. When tumors were inhibited, the levels of PDK and LDHA were decreased in tumors [36]. GLUT1, a key protein to responsible for elevated glucose transport, was overexpressed under hypoxia condition in cancer cells [37]. In addition, VEGF was considered as an another target gene of HIF-1a [38]. It was well-known that VEGF was overexpressed in tumors and involved in tumor angiogenesis and migration [39]. Furthermore, we found the concrete connection of FBP1 and PDK1. All these results indicated that the anti-cancer property of FBP1 might be regulated by reduced expressions of these glucose metabolic pathway related genes via inhibiting HIF-1 1 level. Unfortunately, a limitation of this study was that the additions of one more luminal-like, basal-like cell lines and non-cancer cells in this study might enhance the clinical significance of our finding, and the further mechanisms of FBP1 in breast cancers should be investigated in more cell lines in the following study. This study reveal that overexpressed FBP1 may repress tumor growth, migration and glycolysis via targeting HIF-1a in BLBC.

Acknowledgements: This work was supported by Innovative scientific research project of Harbin Medical University.

\section{References}

[1] JEMAL A, BRAY F, CENTER MM, FERLAY J, WARD E et al. Global cancer statistics. CA Cancer J Clin 2011; 61: 69-90. https://doi.org/10.3322/caac.20107

[2] LECH R, PRZEMYSLAW O. Epidemiological models for breast cancer risk estimation. Ginekol Pol 2011; 82: 451-454.

[3] PEROU CM, SORLIE T, EISEN MB, VAN DE RIJN M, JEFFREY SS et al. Molecular portraits of human breast tumours. Nature 2000; 406: 747-752. https://doi. $\underline{\operatorname{org} / 10.1038 / 35021093}$

[4] SORLIE T, PEROU CM, TIBSHIRANI R, AAS T, GEISLER S et al. Gene expression patterns of breast carcinomas distinguish tumor subclasses with clinical implications. Proc Natl Acad Sci U S A 2001; 98: 10869-10874. https://doi.org/10.1073/ pnas. 191367098

[5] LUNDGREN K, NORDENSKJ LD B, LANDBERG G. Hypoxia, Snail and incomplete epithelial-mesenchymal transition in breast cancer. Br J Cancer 2009; 101: 1769-1781. https:// doi.org/10.1038/sj.bjc.6605369

[6] VAUPEL P, MAYER A, HOCKEL M. Tumor hypoxia and malignant progression. Methods Enzymol 2004; 381: 335-354. https://doi.org/10.1016/S0076-6879(04)81023-1

[7] VAUPEL P, SCHLENGER K, KNOOP C, HOCKEL M. Oxygenation of human tumors: evaluation of tissue oxygen 
distribution in breast cancers by computerized $\mathrm{O} 2$ tension measurements. Cancer Res 1991; 51: 3316-3322.

[8] SEMENZA GL. Oxygen sensing, homeostasis, and disease. N Engl J Med 2011; 365: 537-547. https://doi.org/10.1056/ NEJMra1011165

[9] GERMAIN S, MONNOT C, MULLER L, EICHMANN A. Hypoxia-driven angiogenesis: role of tip cells and extracellular matrix scaffolding. Curr Opin Hematol 2010; 17: 245-251. https://doi.org/10.1097/moh.0b013e32833865b9

[10] WANG GL, JIANG BH, RUE EA, SEMENZA GL. Hypoxiainducible factor 1 is a basic-helix-loop-helix-PAS heterodimer regulated by cellular O2 tension. Proc Natl Acad Sci U S A 1995; 92: 5510-5514. https://doi.org/10.1073/pnas.92.12.5510

[11] SCHOFIELD CJ, RATCLIFFE PJ. Oxygen sensing by HIF hydroxylases. Nat Rev Mol Cell Biol 2004; 5: 343-354. https:// doi.org/10.1038/nrm1366

[12] VAUPEL P. The role of hypoxia-induced factors in tumor progression. Oncologist 2004; 9 Suppl 5: 10-17. https://doi. org/10.1634/theoncologist.9-90005-10

[13] POUYSSEGUR J, DAYAN F, MAZURE NM. Hypoxia signalling in cancer and approaches to enforce tumour regression. Nature 2006; 441: 437-443. https://doi.org/10.1038/na$\underline{\text { ture } 04871}$

[14] RAKHA EA, ELSHEIKH SE, ALESKANDARANY MA, HABASHI HO, GREEN AR et al. Triple-negative breast cancer: distinguishing between basal and nonbasal subtypes. Clin Cancer Res 2009; 15: 2302-2310. https://doi. org/10.1158/1078-0432.CCR-08-2132

[15] TAN EY, YAN M, CAMPO L, HAN C, TAKANO E et al. The key hypoxia regulated gene CAIX is upregulated in basal-like breast tumours and is associated with resistance to chemotherapy. Br J Cancer 2009; 100: 405-411. https://doi. org/10.1038/sj.bjc.6604844

[16] CANCER GENOME ATLAS NETWORK. Comprehensive molecular portraits of human breast tumours. Nature 2012; 490: 61-70. https://doi.org/10.1038/nature11412

[17] KOPPENOL WH, BOUNDS PL, DANG CV. Otto Warburg's contributions to current concepts of cancer metabolism. Nat Rev Cancer 2011; 11: 325-337. https://doi.org/10.1038/ $\underline{\operatorname{nrc} 3038}$

[18] WEIDEMANN A, JOHNSON RS. Biology of HIF-1a. Cell Death Differ 2008; 15: 621-627. https://doi.org/10.1038/ cdd.2008.12

[19] MIZUNUMA H, TASHIMA Y. Fructose-1,6-biphosphatase of the small intestine. Purification and comparison with liver and muscle fructose-1,6-bisphosphatases. J Biochem 1978; 84: 327-336. https://doi.org/10.1093/oxfordjournals.jbchem. $\underline{\mathrm{a} 132132}$

[20] TILLMANN H, ESCHRICH K. Isolation and characterization of an allelic cDNA for human muscle fructose-1,6-bisphosphatase. Gene 1998; 212: 295-304. https://doi.org/10.1016/ S0378-1119(98)00181-4

[21] CHEN M, ZHANG J, LI N, QIAN Z, ZHU M et al. Promoter hypermethylation mediated downregulation of FBP1 in human hepatocellular carcinoma and colon cancer. PLoS One 2011; 6: e25564. https://doi.org/10.1371/journal. pone.0025564
[22] LIU X, WANG X, ZHANG J, LAM EK, SHIN VY et al. Warburg effect revisited: an epigenetic link between glycolysis and gastric carcinogenesis. Oncogene 2010; 29: 442-450. https:// doi.org/10.1038/onc.2009.332

[23] LI B, QIU B, LEE DS, WALTON ZE, OCHOCKI JD et al. Fructose-1,6-bisphosphatase opposes renal carcinoma progression. Nature 2014; 513: 251-255. https://doi.org/10.1038/ nature 13557

[24] BIGL M, JANDRIG B, HORN LC, ESCHRICH K. Aberrant methylation of human L- and M-fructose 1,6-bisphosphatase genes in cancer. Biochem Biophys Res Commun 2008; 377: 720-724. https://doi.org/10.1016/j. bbrc.2008.10.045

[25] ZENG Z, ZHANG C, CHEN J. Lentivirus-mediated RNA interference of DC-STAMP expression inhibits the fusion and resorptive activity of human osteoclasts. J Bone Miner Metab 2013; 31: 409-416. https://doi.org/10.1007/s00774013-0434-0

[26] GENERALI D, BERRUTI A, BRIZZI MP, CAMPO L, BONARDI $S$ et al. Hypoxia-inducible factor-1alpha expression predicts a poor response to primary chemoendocrine therapy and disease-free survival in primary human breast cancer. Clin Cancer Res 2006; 12: 4562-4568. https://doi. org/10.1158/1078-0432.CCR-05-2690

[27] ZHONG H, DE MARZO AM, LAUGHNER E, LIM M, HILTON DA et al. Overexpression of hypoxia-inducible factor lalpha in common human cancers and their metastases. Cancer Res 1999; 59: 5830-5835.

[28] TALKS KL, TURLEY H, GATTER KC, MAXWELL PH, PUGH CW et al. The expression and distribution of the hypoxia-inducible factors HIF-1alpha and HIF-2alpha in normal human tissues, cancers, and tumor-associated macrophages. Am J Pathol 2000; 157: 411-421. https://doi.org/10.1016/ S0002-9440(10)64554-3

[29] TRASTOUR C, BENIZRI E, ETTORE F, RAMAIOLI A, CHAMOREY E et al. HIF-1alpha and CA IX staining in invasive breast carcinomas: prognosis and treatment outcome. Int J Cancer 2007; 120: 1451-1458. https://doi.org/10.1002/ ijc. 22436

[30] HUBBI ME, SEMENZA GL. Regulation of cell Pproliferation by hypoxia-inducible factors. Am J Physiol Cell Physiol 2015; 309: C775-782. https://doi.org/10.1152/ ajpcell.00279.2015

[31] TIAN Q, XUE Y, ZHENG W, SUN R, JI W et al. Overexpression of hypoxia-inducible factor $1 \alpha$ induces migration and invasion through Notch signaling. Int J Oncol 2015; 47: 728-738. https://doi.org/10.3892/ijo.2015.3056

[32] TENNANT DA, DURAN RV, GOTTLIEB E. Targeting metabolic transformation for cancer therapy. Nat Rev Cancer 2010; 10: 267-277. https://doi.org/10.1038/nrc2817

[33] BAKER L, BOULT J, WALKER-SAMUEL S, CHUNG Y, JAMIN Y et al. The HIF-pathway inhibitor NSC-134754 induces metabolic changes and anti-tumour activity while maintaining vascular function. Br J Cancer 2012; 106: 1638-1647. https:// doi.org/10.1038/bjc.2012.131

[34] IYER NV, KOTCH LE, AGANI F, LEUNG SW, LAUGHNER $\mathrm{E}$ et al. Cellular and developmental control of $\mathrm{O} 2$ homeostasis 
by hypoxia-inducible factor 1a. Genes Dev 1998; 12: 149-162. https://doi.org/10.1101/gad.12.2.149

[35] KIM JW, TCHERNYSHYOV I, SEMENZA GL, DANG CV. HIF-1-mediated expression of pyruvate dehydrogenase kinase: A metabolic switch required for cellular adaptation to hypoxia. Cell Metab 2006; 3: 177-185. https://doi.org/10.1016/j. cmet.2006.02.002

[36] WARD PS, THOMPSON CB. Signaling in control of cell growth and metabolism. Cold Spring Harb Perspect Biol 2012; 4: a006783.

[37] BEHROOZ A, ISMAIL-BEIGI F. Dual control of glut1 glucose transporter gene expression by hypoxia and by inhibition of oxidative phosphorylation. J Biol Chem 1997; 272: 5555-5562. https://doi.org/10.1074/jbc.272.9.5555

[38] FORSYTHE JA, JIANG BH, IYER NV, AGANI F, LEUNG SW et al. Activation of vascular endothelial growth factor gene transcription by hypoxia-inducible factor 1 . Mol Cell Biol 1996; 16: 4604-4613. https://doi.org/10.1128/ $\underline{\text { MCB.16.9.4604 }}$

[39] RAPISARDA A, MELILLO G. Role of the VEGF/VEGFR Axis in Cancer Biology and Therapy. Adv Cancer Res 2012; 114: 237-267. https://doi.org/10.1016/B978-0-12-3865038.00006-5 